\title{
De quoi l'année 1980 est-elle le nom?
}

Jérôme Meizoz et Gilles Philippe

\section{(2) OpenEdition}

Journals

Édition électronique

URL : http://journals.openedition.org/edl/1932

DOI : 10.4000/edl.1932

ISSN : 2296-5084

\section{Éditeur}

Université de Lausanne

\section{Édition imprimée}

Date de publication : 15 mars 2020

Pagination : $9-12$

ISBN : 978-2-940331-73-4

ISSN : 0014-2026

\section{Référence électronique}

Jérôme Meizoz et Gilles Philippe, «De quoi l'année 1980 est-elle le nom? », Études de lettres [En ligne], 312 | 2020, mis en ligne le 24 mars 2020, consulté le 10 décembre 2020. URL : http:// journals.openedition.org/edl/1932; DOI : https://doi.org/10.4000/edl.1932 


\section{DE QUOI L'ANNÉE 1980 EST-ELLE LE NOM?}

On se souvient d'abord d'une année par ses morts. 1980 vit disparaître Jean-Paul Sartre, Roland Barthes, Alfred Hitchcock, Oskar Kokoschka, Joe Dassin, John Lennon...

Mais 1980 fut aussi l'année où cinquante pays boycottèrent les Jeux olympiques de Moscou, l'année des événements de Gdansk, qui annonçaient la reconfiguration de l'Europe, l'année où Margaret Thatcher commença à imposer sa révolution conservatrice, donnant une impulsion décisive aux politiques néolibérales qui devaient bientôt triompher dans l'ensemble de l'Occident. Ce fut aussi l'année de la création du «Parti du peuple indien", celle de la première mention du «dérèglement climatique» au Congrès américain. Ce fut encore l'année de la "Couleur menthe à l'eau » d'Eddy Mitchell (d'où la couverture du présent volume), d'une célèbre chanson de Renaud, d'un album décisif de Trust, du succès du Nom de la rose et d'ouvrages désormais classiques de Pierre Bourdieu, Oswald Ducrot, Alice Rivaz, etc. Sur les écrans, on projetait La boum, Sauve qui peut (la vie), L'empire contre-attaque...

1980 est également la date que les historiens de la littérature retiennent usuellement comme l'an zéro de notre contemporanéité. Et bien des sociologues font naître en 1980 les premiers enfants de la "génération Y", celle qui dicte aujourd'hui la norme esthétique et idéologique. Ce seront les enfants de la postmodernité: Jean-François Lyotard vient tout juste de faire paraître La condition postmoderne; notre rapport au temps vient de muter: nous serons désormais des post-.

Pour ce volume d'Études de lettres, nous avons souhaité procéder à une expérience interdisciplinaire et inviter les chercheuses et chercheurs de la Faculté des lettres de l'Université de Lausanne à interroger ce 
possible seuil, en leur posant cette simple question: pour vous ou dans votre domaine, de quoi l'année 1980 est-elle le nom? La mosaïque des réponses dessine une sorte de portrait chinois de l'an 80 (doit-on dire "quatre-vingts"? peut-on dire "huitante» ?) en une cinquantaine de tesselles littéraires, artistiques, culturelles, sociales, politiques, scientifiques, technologiques, philosophiques, intellectuelles...

Les auteurs du volume font la part belle à des émergences (le cyberpunk, le micro-ordinateur, le new journalism américain) et à des renouveaux (le retour de l'auteur et du sujet; l'aggiornamento des études constantiennes). Ils décrivent des seuils et des tournants propres à divers champs culturels (l'art contemporain à la Biennale de Venise; la littérature de grande diffusion; la libéralisation de l'audiovisuel public en Suisse). La plupart des articles prennent leur source dans l'actualité de 1980 (un scandale télévisuel; un défilé d'Yves Saint Laurent; les émeutes de la jeunesse et le mouvement punk; une polémique autour de Marcel Bénabou) et commentent en détail nombre d'événements culturels de l'année (le suicide de Romain Gary; les livres de Norman Mailer, de Paolo Volponi, de Giorgio Bassani; l'éloge du fragmentaire par Julien Gracq; les mutations commerciales des musiques actuelles). En 1980, Roland Barthes médite sur la photographie, tandis que le romancier Jean-Luc Benoziglio s'empare des encyclopédies.

Paul Zumthor prend sa retraite, mais les sciences humaines poursuivent leur éternel renouvellement: le développement de la sociolinguistique historique accompagne des débats plus techniques sur le fonctionnement de la langue; un mot, "énonciation", titille l'analyse littéraire et cinématographique, et la rhétorique revient à la mode. Mais la politique est partout: la parution du premier atlas linguistique du Québec coïncide avec le premier référendum sur la souveraineté du pays; les méthodes de langue elles-mêmes adoptent une teinte néolibérale. Grâce à Carlo Ginzburg, l'histoire se fait micro-, mais les historiens débattent aussi de l'affaire Faurisson, et la parution de Maus d'Art Spiegelman nous rappelle que les vieux démons ne sont pas tous chassés.

Loin des bruits du monde, on lit encore Homère, mais à Bucarest comme ailleurs on parle de Solidarność, tandis qu'un Polonais reçoit le prix Nobel de littérature et que des écrivains de la diaspora russe font une tournée sur les campus américains. Les femmes, elles, poursuivent leur long combat: en Suisse, on débat de leur pension, et pour la première fois le "Grand Prix C. F. Ramuz" couronne une lauréate; une 
célèbre autrice anglaise invite à relire Colette; en France, un philosophe assassine son épouse, tandis que pour la première fois une femme entre à l'Académie française.

Un tel projet n'est pas sans précédent; il s'inscrit dans la lignée d'ouvrages déjà existants, proposant des entrées sur une année précise, comme celui de Marc Angenot sur 1889, celui de Jean-Michel Rabaté sur 1913, celui de Kevin Jackson sur 1922, ou encore les collectifs dirigés par Pierre Brunel et Danielle Chauvin sur 1939 ou par David Martens et Bart Van Den Bossche sur 1947, etc. La coupe synchronique constitue évidemment un artifice à double tranchant pour les historiens: aucune archive ne saurait se ranger aussi sagement dans une seule année. Tous ces articles en appellent donc à des contextualisations plus larges à partir de l'événement retenu.

Pour mieux comprendre encore ce que fut l'année 1980, on pourra lire en parallèle ou en complément de ce volume le livre de Philippe Artières, Miettes. Eléments pour une histoire infra-ordinaire de l'année 1980 (Verticales, 2016) ou celui de François Cusset, La décennie. Le grand cauchemar des années 1980 (La Découverte, 2006). Et l'on pourra bien sûr rouvrir L'été 80 de Marguerite Duras (Minuit, 1980).

On arrivera alors à cette conclusion à la fois décevante, fascinante et rassurante: 1980 fut finalement une année comme tant d'autres dans l'histoire et la mémoire de l'Europe, à la fois extraordinairement riche et merveilleusement banale.

Jérôme Meizoz

Section de français et Formation Doctorale interdisciplinaire,

Faculté des lettres, Université de Lausanne Gilles Philippe

Section de français, Faculté des lettres, Université de Lausanne 
